\title{
New telomeres in yeast are initiated with a highly selected subset of $\mathbf{T G}_{1-3}$ repeats
}

\author{
Kate M. Kramer and James E. Haber ${ }^{1}$ \\ Rosenstiel Basic Medical Sciences Research Center and Department of Biology, Brandeis University, Waltham, \\ Massachusetts 02254-9110 USA
}

\begin{abstract}
The creation of new telomeres was studied by generating a site-specific double-strand break in diploid strains of Saccharomyces cerevisiae that are unable to carry out homologous recombination. New telomere formation occurred $\sim 1 \%$ of the time but only when $\left(T_{2} G_{4}\right)_{13}$ was present proximal to the break site. About half of the healing events occurred at a number of 1- to 9-bp G or G,T sequences located as far as 128 bp distal to the $T_{2} G_{4}$ repeats. Surprisingly, in 16 events at sites ending in GTGG, the first $T_{G_{1-3}}$ nucleotides added always included either an 11- or a 13-bp sequence (GTGTGGGTGTG or GTGTGTGGGTGTG), after which each new telomere diverged into a less ordered $\mathrm{TG}_{1-3}$ pattern. Moreover, at $75 \%$ of the remaining addition sites, these same 11- or 13-bp sequences were found overlapping the junction between the chromosomal primer and the newly added sequences. We propose that short $G, T$ sequences near an organizing sequence such as $\left(T_{2} G_{4}\right)_{13}$ can act as primers to pair with the template RNA of a telomerase and add new sequences that are complementary to that RNA.
\end{abstract}

[Key Words: Broken chromosome repair; Saccharomyces cerevisiae; new telomere formation]

Received August 18, 1993; revised version accepted September 27, 1993.

The stability of linear chromosomes depends on the presence of telomeres at their ends. Telomeres function both to ensure the complete replication of chromosome ends and to protect them from degradation, recombination, and fusion with other chromosomes (for review, see Blackburn 1992; Blackburn and Szostak 1984; Zakian 1989; Biessmann and Mason 1992). Most eukaryotic telomeres consist of $\mathrm{G}$-rich simple repeat sequences at the chromosome terminus, for example, $T_{2} G_{4}, T_{4} G_{4}$ or $\mathrm{T}_{2} \mathrm{AG}_{3}$. The conservation of telomere sequences among evolutionarily diverse organisms suggests that they all share a common structure and function. The mechanism by which telomeric repeats are added on to a preexisting array have been well documented in ciliates /Greider and Blackburn 1985, 1987, 1989; Zahler and Prescott 1988; Shippen-Lenz and Blackburn 1989) and in both mice and humans (Morin 1991; Prowse et al. 1993). In these cases, highly regular telomere repeats are added by an RNAdependent DNA polymerase (telomerase) in which the $3^{\prime}$ end of the preexisting telomere sequence acts as a primer for the addition of new telomere repeats. It is not yet clear, however, whether the yeast Saccharomyces cerevisiae telomere repeats, an irregular array of $\mathrm{TG}_{1-3}$ sequences, are added by a telomerase mechanism.

In some circumstances, telomeres are synthesized de novo. New telomeres can be created as part of a geneti-

${ }^{1}$ Corresponding author. cally programmed phase of cellular development and differentiation. For example, the Tetrahymena telomerase adds telomere repeats to the ends of fragmented chromosomes during macronuclear development, at sites where no telomeric repeats are present (Yu and Blackburn 1991). Similar programmed telomere addition also occurs in Ascaris (Müller et al. 1991). New telomeres can also be formed to repair chromosomes broken by mechanical rupture or other stress. McClintock (1941) first described such "healing" of broken chromosomes, and similar events have been documented in yeast (McCusker and Haber 1981; Haber and Thorburn 1984; Surosky et al. 1986; Jäger and Philippsen 1989; Kämper et al. 1989). Spontaneously truncated chromosomes have also been found in organisms as diverse as malaria (Pologe and Ravetch 1988; Scherf and Mattei 1992) and humans (Wilkie et al. 1990).

In $S$. cerevisiae new $\mathrm{TG}_{1-3}$ telomeric sequences are efficiently added onto transformed linear plasmids carrying heterologous telomere repeats from a variety of organisms (for review, see Zakian 1989; Biessmann and Mason 1992). There is yet no direct evidence of telomerase activity in yeast; however, a strong candidate gene for the yeast telomerase has been described in the gene EST1 (Lundblad and Szostak 1989). RAD52-independent recombination has been proposed as an alternative mechanism for the addition and maintenance of yeast $\mathrm{TG}_{1-3}$ (Wang and Zakian 1990b; Biessmann and Mason 
1992). This suggestion is based on the observation of recombination between heterologous Tetrahymena $\mathrm{T}_{2} \mathrm{G}_{4}$ repeats and Oxytricha $\mathrm{T}_{4} \mathrm{G}_{4}$ repeats on opposite ends of a newly introduced linear yeast artificial chromosome (Pluta and Zakian 1989; Wang and Zakian $1990 \mathrm{a})$. On the basis of these results it has been argued that yeast chromosome ends may sometimes acquire telomeric $\mathrm{TG}_{1-3}$ de novo by a $R A D 52$-independent recombinational pathway. However, this model does not easily account for how new telomeres could be added on to nontelomeric sequences that frequently intervene between heterologous telomere repeats on transformed linear plasmids and the newly added $\mathrm{TG}_{1-3}$ (Murray et al. 1988; Wang and Zakian 1990b). It has been argued that this may occur by a copy choice mechanism or slippage during DNA synthesis (Wang and Zakian 1990b; Biessmann and Mason 1992).

To learn more about the way that new telomere addition occurs in yeast, we have developed a simple system to generate specific chromosome breaks that can be repaired by de novo telomere formation. Our goal was to examine the actual sequences added at new telomeres, to establish whether these events were likely to have arisen by telomerase activity or by recombination. Our sequence analysis of new telomere addition sites leads us to propose that new $\mathrm{TG}_{1-3}$ sequences are added by the action of a telomerase rather than by recombination. We base our model on the following observations. First, new telomere sequences can be added in a RAD52 independent manner to short stretches (1-9 bp) of G, T sequence located up to $100 \mathrm{bp}$ distal to an essential $\left(T_{2} G_{4}\right)_{13}$ organizing sequence. In some cases, the substrates for addition are as short as a single G, GT, GG, or GTG. Second, the junction at the chromosomal addition site frequently contains one of two specific 11- or 13-bp motifs. Finally, the specific $\mathrm{TG}_{1-3}$ sequences that are added to a given site are strongly influenced by the DNA sequence at that site.

\section{Results}

\section{Generating terminally deleted chromosomes}

The strategy that we have used is illustrated in Figure 1. A site-specific chromosome break is introduced at the mating-type (MAT) locus on chromosome III by galactose-regulated induction of the $\mathrm{HO}$ endonuclease gene (Jensen and Herskowitz 1984; Connolly et al. 1988). In the absence of RAD52 function, this double-strand break (DSB) cannot be repaired by homologous recombination, either with the silent copy donor sequences $H M L$ or $H M R$ or with the MAT information on the opposite chromosome (Weiffenbach and Haber 1981). Diploids containing terminally deficient, healed chromosomes can then be recovered by genetic screening. Ten kilobases proximal to the break site, the broken chromosome carries the URA3 marker and $13 \mathrm{~T}_{2} \mathrm{G}_{4}$ repeats flanked on the distal side by nontelomeric DNA. We reasoned that if new telomere formation could not occur at any of the sequences in the $10-\mathrm{kb}$ interval adjacent to the break site, the $T_{2} G_{4}$ repeats would act as a possible "default" site.

Diploids of strain PA104T $\times$ RS200L (Table 1) carrying terminally deficient chromosomes are expected to be $\mathrm{Ura3}^{+}$but $\mathrm{Thr}^{-}{ }^{-}$; therefore, strains with this phenotype were analyzed for their karyotype by contour-clamped homogeneous electric fields (CHEF) gel electrophoresis and Southern blot analysis (see Materials and methods).
Figure 1. Generating a terminally deficient chromosome III. Schematic diagrams of chromosome III are shown. (A) The rad52 strain PA104T was marked by an insertion of URA3::(TTGGGG) $13:$ :pBR322, $10 \mathrm{~kb}$ proximal to the $\mathrm{HO}$ cut site. [In strains YKK104BX1, YKK104BX2, and YKK104BX3 the pBR322 sequences are replaced by BX1, $\mathrm{BX} 2$, and $\mathrm{BX} 3$ sequences (see Materials and methods)|. A DSB was generated at MATa on chromosome III in PA104T following $\mathrm{HO}$ endonuclease expression from a $G A L:: H O$ plasmid. The DSB is degraded by extensive $5^{\prime} \rightarrow 3^{\prime}$ exonuclease activity (White and Haber 1990) such that MATa gene functions are disrupted. The degradation of $\sim 400$ bp of $\alpha$ sequences causes cells to become phenotypically Mat $\alpha 2^{-}$Mat $\alpha 1^{-}$ and exhibit an a-mating behavior (Weiffenbach and Haber 1981). These a-mating cells were then rescued by mating to either a RAD52 (RS200L) or a rad52 (YKK611) $M A T \alpha$ haploid carrying the distal, recessive marker thr4 on chromosome III. (B) The DSB was induced in a MATa/MATa-inc diploid (YKK910) homozygous for rad52. In the YKK910 diploid, only the MATa locus can be cut by HO endonuclease (Weiffenbach et al. 1983). Silent mating-type cassettes $H M L$ and $H M R$ are indicated. (B) BamHI; (S) SmaI; (H) HindIII; (X) XbaI; (R) EcoRI.

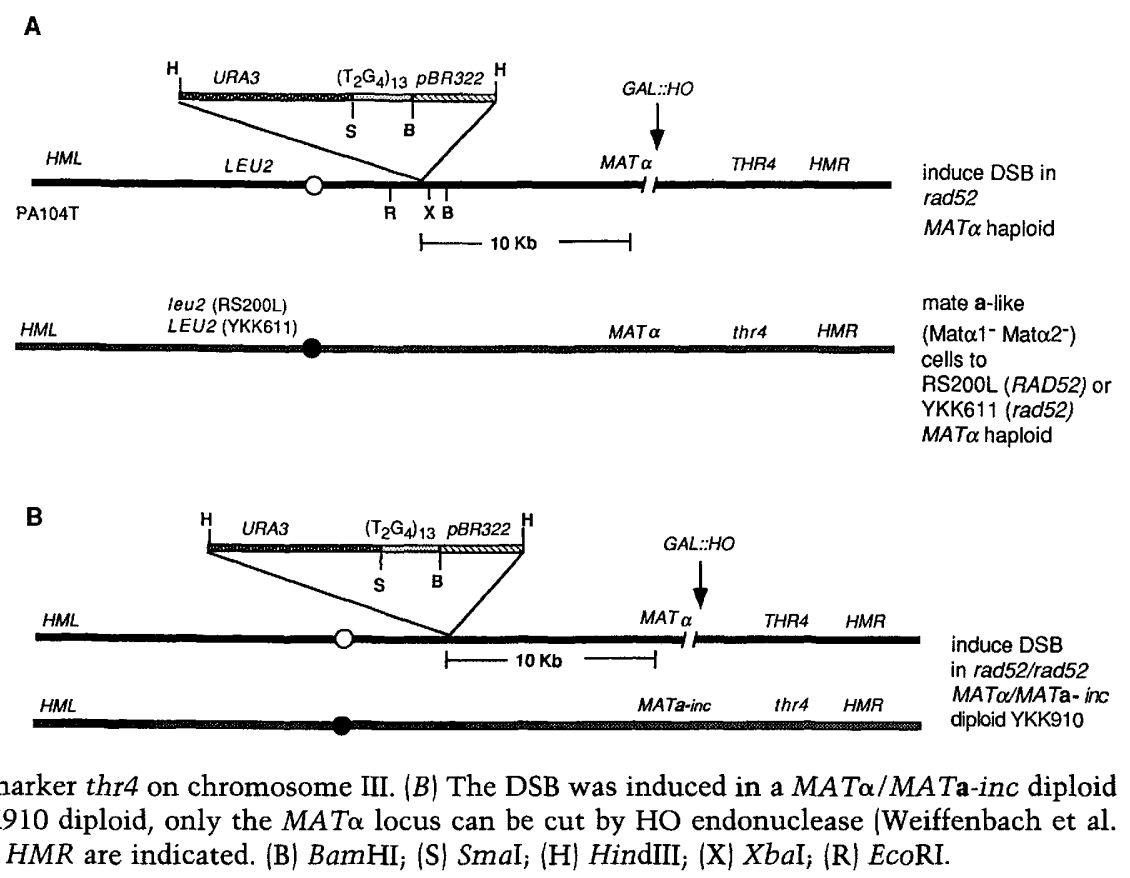

B 
Table 1. Yeast strains

\begin{tabular}{|c|c|}
\hline Strain & Genotype \\
\hline PA104T $^{\mathrm{a}}$ & 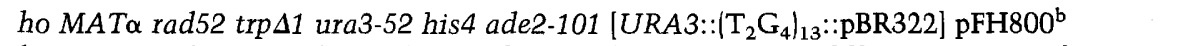 \\
\hline YKK104HO & 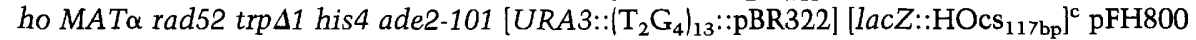 \\
\hline 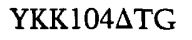 & ho MATa rad52 trp $\Delta 1$ his4 ade2-101 [URA3::pBR322] pFH00 \\
\hline YKK104BX1 & 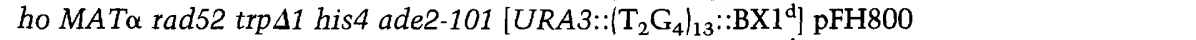 \\
\hline YKK104BX2 & ho MAT $\alpha$ rad52 trp $\Delta 1$ his 4 ade2-101 [URA3::( $\left.\left.\mathrm{T}_{2} \mathrm{G}_{4}\right)_{13}:: \mathrm{BX} 2^{\mathrm{d}}\right]$ pFH800 \\
\hline YKK104BX3 & ho MAT $\alpha$ rad52 trp $\Delta 1$ his 4 ade2-101 [URA3::( $\left.\left.\mathrm{T}_{2} \mathrm{G}_{4}\right)_{13}:: \mathrm{BX}^{\mathrm{d}}\right]$ pFH800 \\
\hline RS200L & ho MAT $\alpha$ thr4 leu2 ura3-52 lys2-801 ade2-101 \\
\hline YKK611 & ho $M A T \alpha$ thr4 leu2 rad52::LEU2 ura3-52 lys2-801 \\
\hline YKK901 $^{\mathrm{e}}$ & ho MATa-inc rad52 thr4 trp1H ura3-52 ade1 \\
\hline YKK910 & YKK901 mated to PA104T \\
\hline YKK1010 & YKK901 mated to YKK104HO \\
\hline YKK910BX1 & YKK901 mated to YKK104BX1 \\
\hline YKK910BX2 & YKK901 mated to YKK104BX2 \\
\hline YKK910BX3 & YKK901 mated to YKK104BX3 \\
\hline
\end{tabular}

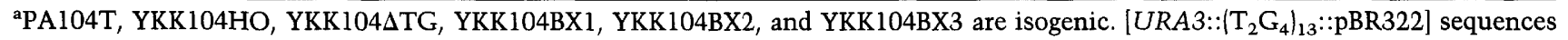
are inserted $10 \mathrm{~kb}$ proximal to $M A T$ (see Fig. 1).

${ }_{\mathrm{b}} \mathrm{pH} 800$, a TRPl CEN4 plasmid carrying a GAL::HO gene was described by Nickoloff et al. (1989).

${ }^{c}$ The HOcs ${ }_{117 b p}$ is described in Fishman-Lobell et al. (1992).

${ }^{\mathrm{d}}$ See Fig. 3 for relevant sequences.

e MATa-inc is described in Weiffenbach et al. (1983).

Southern blots of chromosome separating gels were probed with $U R A 3$ sequences (Fig. $2 \mathrm{~A}$ ) because the DSB was always generated on the copy of chromosome III carrying the inserted URA3 marker. In diploids with terminal deletions, the URA3-marked chromosome is dramatically shortened, consistent with its having lost sequences distal to the HO cut site. Diploids containing terminally deficient chromosomes were recovered in $0.2-1 \%$ of cells (Table 2 ), indicating that new telomere formation is not highly efficient.
Healing by de novo telomere addition requires $T_{2} G_{4}$ repeats

The chromosome in which the DSB was induced carried an inserted DNA fragment containing a URA3 marker, 13 repeats of Tetrahymena $\mathrm{T}_{2} \mathrm{G}_{4}$ and $341 \mathrm{bp}$ of pBR322 DNA, all located $10 \mathrm{~kb}$ proximal to the HO cut site (Fig. 1). When we examined (by Southern blot analysis) DNA from diploids containing healed chromosomes, we found that all of them had undergone chromosomal rearrange-
A

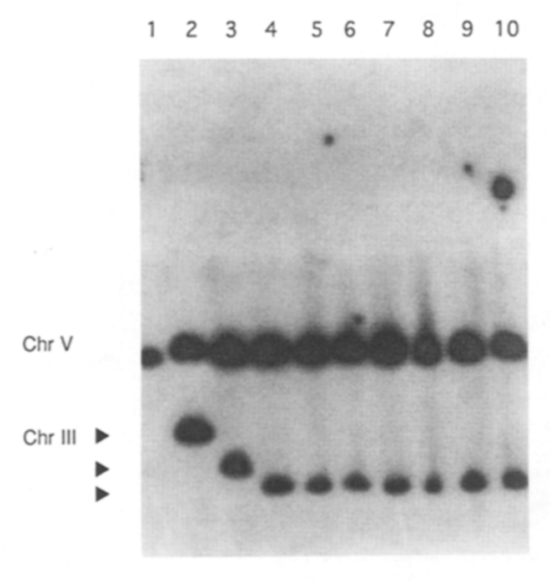

B

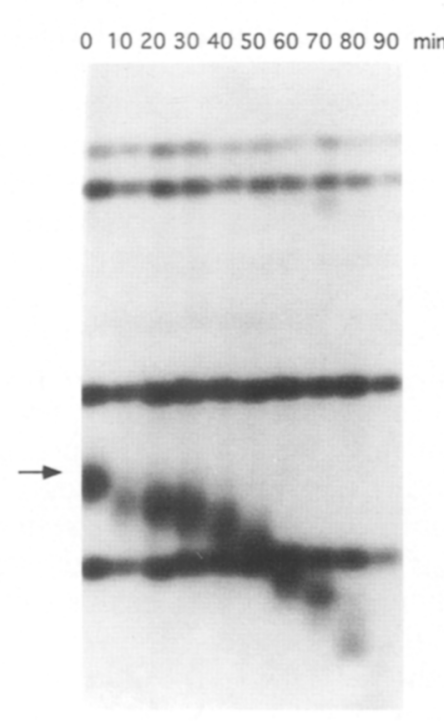

Figure 2. Analysis of $\mathrm{Ura}^{+} \mathrm{Thr}^{-}$diploids. (A) CHEF gel analysis of $\mathrm{Ura}^{+} \mathrm{Thr}^{-}$diploids probed with URA3 sequences. The URA3 probe hybridizes to the ura3-52 locus on chromosome $\mathrm{V}$ (top) and to URA3 inserted on chromosome III (top arrowhead). (Lane 1) Parental RAD52 strain (RS200L); (lane 2) parental rad52 strain (PA104T) before the DSB is induced; (lane 3) a diploid containing a large internal deletion between $M A T$ and its donor locus, HMR (Hawthorne 1963; Haber et al. 1980), was recovered and serves as a convenient marker (middle arrowhead); (lanes 4-10; $\mathrm{Ura}^{+} \mathrm{Thr}^{-}$diploids carrying a terminally deleted chromosome III (bottom arrowhead). $(B)$ Southern blot of genomic DNA from a terminally deleted chromosome III treated with exonuclease Bal31. A sample of genomic DNA was removed before addition of Bal31, and subsequent samples were removed at $10-\mathrm{min}$ intervals. DNA was digested with HindIII before running on the gel. The probe is URA3. The band corresponding to the URA3:: $\left(\mathrm{T}_{2} \mathrm{G}_{4}\right)_{13}$ insert is indicated by an arrow; the other bands correspond to internally located $U R A 3$ sequences on chromosome $\mathrm{V}$. 
Table 2. Types and frequencies of DSB healing events

\begin{tabular}{|c|c|c|c|}
\hline Strain background & Chromosome loss & Recombination & Terminal deletion \\
\hline $\operatorname{rad52}(\mathrm{PA} 104 \mathrm{~T}) \times \operatorname{Rad52}(\mathrm{YKK} 200 \mathrm{~L})^{\mathrm{a}}$ & $229 / 701 \quad|32 \%\rangle$ & $461 / 701 \quad(66 \%)$ & $7 / 1300 \quad(0.5 \%)$ \\
\hline $\operatorname{rad52}(\mathrm{PA} 104 \mathrm{~T}) \times \operatorname{rad52}(\mathrm{YKK} 611)^{\mathrm{b}}$ & $\sim 2448 / \sim 2500(97.9 \%)$ & $22 / \sim 2500(0.9 \%)$ & $30 / \sim 2500(1.2 \%)$ \\
\hline rad52/rad52 (YKK910) & $\sim 2267 / \sim 2300(98.6 \%)$ & $28 / \sim 2300(1.2 \%)$ & $5 / \sim 2300(0.2 \%)$ \\
\hline rad52/rad52 (YKK1010)|lacZ::HOcs ${ }_{117 \mathrm{bp}}$ & $\sim 4874 / \sim 5000(97.5 \%)$ & $20 / \sim 5000(0.4 \%)$ & $106 / \sim 5000(2.0 \%)$ \\
\hline rad52 $(\mathrm{PA} 104 \Delta \mathrm{TG}) \times \operatorname{rad52}(\mathrm{YKK} 611)\left(\mathrm{T}_{2} \mathrm{G}_{4}\right)_{13}$ deleted & $\sim 1280 / 1300 \quad(98.5 \%)$ & $20 / \sim 1300(1.5 \%)$ & $0 / \sim 1300(<0.08 \%)^{\mathrm{c}}$ \\
\hline
\end{tabular}

Healed diploids were classified into three general categories by genetic phenotype and by CHEF gel analysis: (1) chromosome loss; (2) recombination; (3) terminal deletion. Numbers indicate independent healing events. For PA104T $\times$ YKK200L diploids a Ura ${ }^{-}$ $\mathrm{Thr}^{-} \mathrm{Leu}^{-}$phenotype was classified as chromosome loss, and a $\mathrm{Ura}^{-} \mathrm{Thr}^{-} \mathrm{Leu}^{+}$phenotype was classified as healing by recombination; in all other strains, a Ura- ${ }^{-} \mathrm{Thr}^{-}$phenotype was classified as chromosome loss, and a $\mathrm{Ura}^{+} \mathrm{Thr}^{+}$phenotype was classified as healing by recombination. In all strains a $\mathrm{Ura}^{+} \mathrm{Thr}^{-}$phenotype was classified as a terminal deletion. In PA104T $\times$YKK200 and PA104DTG $\times$ YKK611 these $\mathrm{Ura}^{+}$, $\mathrm{Thr}^{-}$diploids were confirmed by CHEF gel analysis.

${ }^{a}$ Data for terminal deletions in this cross were derived from a separate set of experiments from chromosome loss and recombination data.

$\mathrm{b} / \sim$ The number of total diploids was estimated from triplicate serial dilutions. Numbers for chromosome loss events were calculated as $\sim$ total diploids - the sum of recombination events + terminal deletion events.

${ }^{c} P<0.05$, by a G-test (Sokal and Rohlf 1969).

ments very close to the inserted sequences. All terminally deleted chromosomes retained the SmaI site that marks the boundary between URA3 and the $\mathrm{T}_{2} \mathrm{G}_{4}$ repeats, but none of them retained the HindIII site that is located $\sim 350 \mathrm{bp}$ distal to the $\mathrm{T}_{2} \mathrm{G}_{4}$ repeats (data not shown). This is significant because it means that there were no terminal deletion events at any other sites in the $10-\mathrm{kb}$ interval between the site of the DSB and the $U R A 3, \mathrm{~T}_{2} \mathrm{G}_{4}, \mathrm{pBR} 322$-containing insert.

We verified that the URA3 marker was adjacent to the chromosome end in strains with a terminally deleted chromosome by treating genomic DNA in a time course with $\mathrm{Bal} 31$ exonuclease, which degrades sequences at the chromosome ends. Southern blots showed that the band corresponding to the URA3 marker was sensitive to $B a l 31$ exonuclease, indicating that $U R A 3$ was next to the chromosome end (Fig. 2B).

Approximately half of the healing events in PA104T $\times$ RS200L involved addition of yeast $\mathrm{TG}_{1-3}$ repeats distal to the Tetrahymena $\mathrm{T}_{2} \mathrm{G}_{4}$ segment. In $\sim 41 \%$ $(16 / 39)$ of the terminally deleted chromosomes, the BamHI site marking the boundary between the $T_{2} G_{4}$ repeats and nontelomere DNA was retained (data not shown), indicating that the new telomeres had been added to pBR322 sequences (Fig. 1). This result is consistent with previous studies reporting telomere addition to nontelomeric sequences immediately distal to $T_{2} G_{4}$ repeats on transformed DNA (Murray et al. 1988; Wang and Zakian 1990b). We observed a similar frequency of new telomere addition to nontelomeric sequences distal to the $\mathrm{T}_{2} \mathrm{G}_{4}$ repeats $(41-24 \%)$ with three other isogenic strains described below, in which different sequences were substituted for pBR322.

The $T_{2} G_{4}$ repeats appear to be absolutely required for new telomere addition. When we repeated these experiments in isogenic diploid strains in which the $U R A 3$ marker was inserted without accompanying $T_{2} G_{4}$ repeats (YKK104ATG $\times$ YKK611; Table 1), we observed no terminal deletions among $\sim 1.3 \times 10^{3}$ diploids (Table 2).
This result is statistically significantly different $(P<0.05)$ from the results obtained in the isogenic strain carrying the $\mathrm{T}_{2} \mathrm{G}_{4}$ repeats, based on a G-test (Sokal and Rohlf 1969).

\section{Addition sites for yeast $T G_{1-3}$ are short stretches of $G, T$ or G-rich DNA}

We have analyzed in detail how new telomeres are formed by sequencing the sites of de novo addition of yeast $\mathrm{TG}_{1-3}$ to broken chromosome ends. It is well documented that Tetrahymena $\mathrm{T}_{2} \mathrm{G}_{4}$ is a good substrate for the de novo addition of yeast $\mathrm{TG}_{1-3}$ sequences (Szostak and Blackburn 1982; Shampay et al. 1984; Murray et al. 1988; Shampay and Blackburn 1989). We therefore chose to look at the cases where nontelomeric DNA was used as the addition site. Events such as these have been described before (Murray et al. 1988) but were not analyzed by DNA sequencing; hence, it was not clear whether particular sequences are required for such events or whether new yeast telomeres are added to random sequences near the $T_{2} G_{4}$ repeats. Forty-six independently isolated junctions containing new telomeres were cloned and sequenced (see Materials and methods). We found that in all 46 events that we have analyzed, very short stretches of $\mathrm{G}, \mathrm{T}$ or $\mathrm{G}$-rich telomere-like sequence were being used as substrates for yeast $\mathrm{TG}_{1-3}$ addition (Fig. 3). Two of the 46 events (BX55 and BX3BC6) are unusual in that they contain deviations from the $T_{1-3}$ pattern within the first 10 nucleotides of newly added telomere sequence; one has a run of $4 \mathrm{G}^{\prime} \mathrm{s}$, and the other contains 2 consecutive T's, respectively. These exceptional events are not artifacts of cloning, as they were confirmed by analysis of independent clones. It is possible that they reflect errors of telomere addition caused by the very short stretches of G,T sequence to which they were added. We will confine further analysis to the 44 other healing events.

The sites of addition to be analyzed had pBR322 se- 
A

pBR322:

gctccgagaacgggtgcgcatagaaa...

ggatccacaggacgggtgtggtcgccatgatcgcgtagtcgatagtggctccaagtagcgaagcgagcaggactgggcggcggccaaagcggtcggacag

gctccgagaacgggtgTGGGTGTGTGGGTGTGGTGTGGGTGTGTGGGTGTGGTGTGGGTGTGGGTGTGGGTGTGTGGG.

ggatccacaggacgggtgtggtcgccatgatcgcgta g tcgatagtgTGTGGGTGTGGGTGTGGGTGTGGTGTGGGTGTGGGTGTGGTGTGT...

BX611D ggatccacaggacgggtgtggtcgccatgatcgcgtagtGTGGGTGTGGGTGTGGTGTGTGTGTGGGTGTGGTGTGTGTGGGTGTGGTG...

$\mathrm{BX}^{+} 9^{+}$ggatcacaggacgggtgtggtGTGGGTGTGTGGGTGTATGTGGGTGTGGTGTGTGGGGGGTGT...

BX611E ggatccacaggacgggtgtggtGTGTGGGTGTGGTGTGGTGT.

BX1034* ggatccacaggacgggtgtggtGTGGTGTGTGTGGGTGTGTGGGTGTGGTGTGGTGTGGTGTGT

$\mathrm{BX188}^{+}$ggatcacaggacgggtgtggGTGTGGGTGTGTGGGTGTGGGTGTGGTGTGGTGTGTGGGTGT..

BX65 $5^{+}$ggatcacaggacgggtgtggGTGTGGGTGTGGGTGTGGTGTGTTGTGTGTGTGTGTGGGTGTG...

$\mathrm{BX} 38^{+}$ggatcacaggacgggtgtggGTGTGGGTGTGGTGTGGGTGTGGGTGTGGTGTGTGGGGGTGTG.

BX611C ggatccacaggacgggtgtggGTGTGGGTGTGGTGTGTGGGTGTGTGTGGGTGTGGGTGTGGT.

BX611H ggatccacaggacgggtgtggGTGTGGGTGTGGTGTGTGTGGGTGTGGGTGTGGG...

BX1026 ggatcacaggacggTGTGTGGGTGTGTGGGTGTGGGTGTGGTGTGGGTGTGTGG...

B BX1 JUNCTIONS

BX1: ggatccactggacggtgggtgtcgccaaagagatcgatagcgagcttagggttagggagcgcatgcctcaacgggtgtggtactctaga

BXl-40 ggatccactggacggtgggtgtcgccaaagagatcgatagcgagct tag ggttagg gagcgccatgcctcaacgggtgtggtGTGTGGGTGTGGGTGTGGGTGTG GGTGTGGTGTGGTGTGTGGGTGTGGTGTGTGGGTGTGGGTGTGTGT.

BX1-75 ggatccactggacggtgggtgtcgccaaagagatcgatagcgagcttagggtagggagcgccatgcctcaacgggtgtggGTGTGGGTGTGGTGTGGGTGTGGGTGTGG

BX1-32 ggatccactggacggtgggtgtcgccaangagatcgatagcgagcttagggtagggagcgccatgcctcaacgggtgtggGTGTGGGTGTGGTGTGTGTGTGGGT

BX1-7 ggatccactggacggtgggtgtcgccaaagagatcgatagcgagcttagggttagggTGTGTGGGTGTGGTGTGTGGTGTGTGTGGGTGTGTGGGTGTGGTG

BX1-64 ggatccactggacggtgggtgtegccaaagagatcgatagcgagcttagggTGTGTGGGTGTGGTGTGTGGGTGTGGTGTGGGTGTGGGTGTGGGTGT

BX1-70 ggatccactggacggtgggtglegccaaagagTGTGTGGGTGTGGGTGTGGTGTGGGTGTGGGTGTGGTGTGGGTGTGTGTGTGGTGTGTGGGT..

BX1-47 ggatccactggacggtgggtgtegTGTGGGTGTGGTGTGTGTGTGGGTGTGGTGTGTGGGTGTGGGTGTGGGTGTGGTGTGT.

BX1-53 ggatcactggacggtgggtgtGGGTGTGGGTGTGGGTGTGTGTGTGGGTGTGGTGTGTGTGTGTGTGTGTGGGTGTGTGTGTGGGTG...

BX1-60 ggatcactggacggtgggtgtGGGTGTGTGGGTGTGGGTGTGGTGTGTGGGTGTGGTGTGTGGGTGTGGTGTGGGTGTGGTGTGT

BX1-65 ggatcactggacggtgggtgtGGTGTGTGTGGGTGTGGGTGTGGTGTGGGTGTGGTGTGGGTGTGGTGTGTGGGTGTGGTGTGG...

BX1-55 ggatcactggacggtgggtgtGTGGGTGTGGTGTGTGGGTGTGGTGTGGGTGTGGTGTGTGGGTGTGGTGTGTGGGTGTGTTGTGTGT.

BX1-52 ggatcactggacggtgTGGGTGTGTGGGTGTGGGTGTGGGTGTGGTGTGTGGGTGTGGTGTGTGTGGGTGTGGGTGTGGGTGT...

BX1-49 ggatccactggTGTGTGGGTGTGGGTGTGGGTGTGGTGTGGGTGT..

C

BX2:

$\mathrm{BX} 2 \mathrm{BC} 1^{*}$

BX2AC3*

$\mathrm{BX} 2 \mathrm{AC5}^{*}$

BX2BB4*

$\mathrm{BX} 2 \mathrm{BB}^{*}$

$\mathrm{BX} 2 \mathrm{CC} 1$

BX2BC5*

BX2CA3*

BX2CB3*

$\mathrm{BX} 2 \mathrm{CC}^{*} *$

BX2AC4*

D

BX3:

BX3CA2

BX3AB3*

BX3CA4*

BX3CA5

BX3BC6*

BX3BC8*

BBX3DB3

BX3BC9

BX3DB
BX2 JUNCTIONS

ggatccacaggactggtggtggcgccaatctaga

ggatccacaggact ggt g gt gg cgccaatctagTGTGTGTGGGTGTGGGTGTGGTGTGTGGGTGTGGTGTGGGTGTGGTG.. ggatccacaggactggtggtggGTGTGTGGGTGTGTGGGTGTGGTGTGGGTGTGGTGTGGGTGTGGGTGTGG... ggatccacaggactggtggtggGTGTGTGGGTGTGGTGTGGGTGTGTGTGTGGGTGTGGTGTGTGGGTGTGGT. ggatccacaggactggtggtggGTGTGTGGGTGTGGGTGTGGTGTGTGGGTGTGTGGGTGTGTGGGTGTGGGT. ggatccacaggactggtggtggGTGTGTGGGTGTGGGTGTGTGGGTGTGGTGTGGTGTGGTGTGGGTGTGGTGTG.. ggatccacaggactggtggtggGTGTGTGGGTGTGGTGTGGTGTGGGTGTGTGGGTGTGGGTGTGGGTGTGGTGT... ggatcacaggactggtggtggGTGTGGGTGTGGTGTGTGTGTGGGTGTGGTGTGTGTGTGGGTGTGGTGTGTGTG... ggatccacaggactggtggtggGTGTGGGTGTGGTGTGTGGGTGTGGGTGTGGTGTGTGGGTGTGTGTGGG.. ggatccacaggactggtggtggGTGTGGGTGTGGTGTGGGTGTGGTGTGGGTGTGGTGTGTGGGTGTGGTGTGT.. ggatccacaggactggtggGTGTGGGTGTGGGTGTGGGTGTGGTGTGTGTGGGTGTGGTGTGTGTGTGGGTGTGT... ggatccacaggactggGTGTGGTGTGTGTGGGTGTGGGTGTGGTGTGTGTGGGTGTGTGGGTGTGGGTGTGGG...

BX3 JUNCTIONS

ggatccacaggactgtggtgggcgccaatctaga(atattgaaagacgcctctgacaacttactgaccatgagcactcuta tuttggaggg ttattt...)

ggatccacaggactgtggtgggcgccaatctagaatattgaaagacgcctctgacaactttactgaccatgagcactctu tttggagggtGTGGTGTGTGGGTGTGGGTGTGGTGTGTGTGGGTGTGGTGTGTGGTGTGT.. ggatccacaggactgtggtgggegTGTGTGGGTGTGGGTGTGGGTGTGGGTGTGTGGGTGTGGGT. ggatccacaggactgtggtgggcgTGGTGTGTGGGTGTGGTGTGTGGGTGTGTGGGTGTGGTGTGT ggatccacaggactgtggtgggegTGTGGGTGTGGGTGTGGGTGTGGTGTGTGTGGGTGTGT... ggatccacaggactgtggtgggcgTGTGGTTGTGGTGTGTGGTGTGTGGGTGTGTGTGG. ggatccacaggactgtggtgggTGTGGTGTGTGGGTGTGGGTGTGGGTGTGGGTGTGGTGTG ggatccacaggactgtggtgggTGTGGGTGTGTGGGTGTGTGGGTGTGTGGGTGTGG.. ggatccacaggactgtggtgggTGTGGGTGTGGTGTGTGGGTGTGTGGGTGTGTGGGTGT. ggatccacaggactgtggtgTGTGTGGGTGTGGTGTGTGGGTGTGGTGTGGGTGTGG...
Figure 3. Sequences of the sites of de novo telomere formation. pBR322 (BX), BX1, $\mathrm{BX} 2$, and $\mathrm{BX} 3$ refer to the original sequence to which new $\mathrm{TG}_{1-3}$ repeats were added. $\mathrm{BX} 1, \mathrm{BX} 2$, and $\mathrm{BX} 3$ are synthetic BamHI$X b a$ I fragments that were used to replace the BamHI-HindIII pBR322 sequences of PA104T in strains YKK104BX1, YKK104BX2, and YKK104BX3, respectively (see Fig. 1). For BX3, sequences distal to the $X b a I$ site are indicated in parentheses, as these sequences were used for de novo telomere addition in strain BX3CA2. Primer sequences used for $\mathrm{TG}_{1-3}$ addition are in boldface type. Newly added $\mathrm{TG}_{1-3}$ repeats are in uppercase letters. Consistently added 11-bp (ADD1) and 13-bp (ADD2) motifs are underlined. We have made the assumption throughout that sequences at the junctions that were present in the original strain are chromosomal sequences (for discussion, see text). $(A)$ Ter-

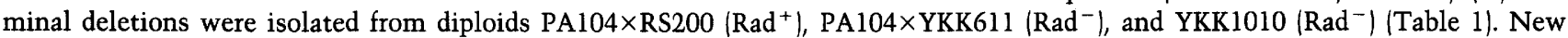
telomeres formed in the $\mathrm{Rad}^{+}$diploid are indicated by a plus sign $(+)$following the strain name. $(B)$ Terminal deletions were isolated from diploid YKK910BX1. $(C)$ Terminal deletions were isolated from diploid YKK910BX2. $(D)$ terminal deletions were isolated from diploid YKK910BX3. (*) Multiple subclones were sequenced (see Materials and methods). In most cases, more telomere sequence could be read than is shown.

quences immediately distal to the $\mathrm{T}_{2} \mathrm{G}_{4}$ repeats (Fig. $3 \mathrm{~A}$ ). The most frequently used telomere addition site contained the telomere-like sequence GGGTGTGGT. Among the nine healing events at this GGGTGTGGT site were three classes. (1) Three events appear to have added new sequences directly to the end of this segment after the removal of all more distal sequences. (We make the parsimonious assumption throughout that any nucleotides that were in the original sequences were preserved, although it is certainly possible that part of the GGGTGTGGT region was degraded and resynthesized during telomere formation). In these three cases, the sequences that are added are all normal $\mathrm{TG}_{1-3}$ sequences but not identical to each other. (2) One event apparently 
involved "chewing back" most of the segment to add at the GG at the $5^{\prime}$ end. (3) Five events have added new telomere DNA after removing the terminal $T$. What is striking about these five independent events is that the first 11 nucleotides that were added are identical (GTGTGGGTGTG, underlined in Fig. 3A), after which the sequences diverge from each other to the unpredictable $\mathrm{TG}_{1-3}$ pattern seen with the other new telomeres. This is a striking result suggesting that some sequences may act as primers for new telomere addition by "setting the frame" of the template so that the next sequences that are added are always the same. For further discussion, we will refer to this conserved, added GTGTGGGTGTG sequence as $\mathrm{ADD} 1$.

We also note that there does not appear to be any difference in the frequency of recovery (Table 2) or in the types of new telomere sequences that were added in the seven cases recovered from $\mathrm{rad52} / \mathrm{rad52}$ diploids (telomeres BX611C, BX611D, BX611E, and BX611H and BX1025, $\mathrm{BX} 1026$, and BX1034 in Fig. $3 \mathrm{~A})$ and the remaining six cases obtained from $R A D 52 /$ rad52 cells. Consistent with this, de novo addition of $\mathrm{TG}_{1-3}$ to the ends of transformed linear plasmids has been shown to be independent of RAD52 function (Dunn et al. 1984; Zakian et al. 1985).

Particular primers promote addition of identical $T G_{1-3}$ sequences

To explore the effect of the primer sequence on the addition of yeast telomere sequences, we constructed three additional strains in which the pBR322 sequences containing the GGGTGTGGT motif were replaced by other possible substrates for telomere addition. The sequences distal to the $B a m \mathrm{HI}$ site, labeled $\mathrm{BX} 1, \mathrm{BX} 2$, and $\mathrm{BX} 3$, are presented in Figure 3. These modified regions were inserted into strains YKK104BX1, YKK104BX2, and YKK104BX3 as described in Materials and methods. Terminally deleted chromosomes were generated and analyzed as described above.

Construct $\mathrm{BX} 1$ differs from the original segment $(\mathrm{BX})$ in three important respects (Fig. 3B). First, the circularly permuted sequence GGTGGGTGT was inserted in place of the preferentially used GGGTGTGGT sequence discussed above. Moreover, to see whether the original preferred site would be used preferentially when it was farther away, this motif was inserted $\sim 90$ bp away from the $\mathrm{T}_{2} \mathrm{G}_{4}$ sequences. Finally, we also included two repeats of the human telomere sequence TTAGGG as a possible addition site. Among 13 healing events analyzed, three used GGGTGTGGT at its more distant location. One (BX1-40) retained the distal $\mathrm{T}$ and proved to add an identical sequence to one of the previous examples (BX611E; Fig. 3A) for the first $12 \mathrm{bp}$. The two other new telomeres were apparently added after the removal of the distal $\mathrm{T}$. Strikingly, in both cases, the same 11-bp ADDl sequence was added as in the BX construct. Again, following $\mathrm{ADD} 1$, the two sequences diverged from each other and from the previous examples. This result substantiates the conclusion that there is a highly preferential addition of the first $11 \mathrm{bp}$ of new telomere sequence when the primer sequence is GGGTGTGG.

When we look at the other 10 healing events with construct $\mathrm{BX} 1,4$ have added new sequences to the $3^{\prime} \mathrm{T}$ of the circularly permuted site, but there is no distinctive order to the first 11 nucleotides added. Thus, not all G,Trich regions appear to fix the order of initial new telomere addition. There were also two additions at the ends of either the first or second TTAGGG repeat; both included same first 20 nucleotides before the sequences diverged.

\section{A different primer yields a different conserved, initially added telomere sequence}

In the construct $\mathrm{BX} 2$, the original preferred site was replaced by TGGTGGTGG. This $\mathrm{TG}_{1-3}$ sequence is never found within authentic telomeres, but it was readily used as a site for new telomere addition (Fig. 3C). Surprisingly, of eight new telomeres added to the end of this segment, three had initiated with the same GTGTGGGTGTG (ADD1) sequence. The remaining five events at this site had a perfectly conserved 13-bp sequence before the $\mathrm{TG}_{1-3}$ sequences diverged from each other. This sequence, GTGTGTGGGTGTG, which we will term $\mathrm{ADD} 2$, is identical to ADD1 except for the presence of an additional GT at the $5^{\prime}$ end. Additionally, in the healing event in $\mathrm{BX} 2 \mathrm{CC} 3$, the TGGTGGTGG region apparently had been "trimmed back" to TGGTGG before addition of the same ADD1 sequence. We note that the terminal 4 nucleotides, all of the ADD1 and ADD2 addition sites (Fig. 3), are GTGG.

Finally, with construct BX3 (Fig. 3D), the preferential site of addition was replaced by another circularly permuted version of the sequence in pBR322, TGTGGTGGG. Of nine events sequenced, there was no fixed order to the first 11 nucleotides added, and 4 new telomeres actually began at a single $G$ separated from the 9-bp G,T sequence by a C. These data provide strong evidence that some primer sequences, but not others, promote the addition of highly ordered initial telomere sequence.

\section{Effect of the position of the DSB on the efficiency of de novo telomere formation}

Healing of a broken chromosome by de novo telomere formation is a rare event $(0.2-1.0 \%)$ when it occurs $10 \mathrm{~kb}$ from the break site. In our experiments, the DNA between the $\mathrm{HO}$ cut site and the $\mathrm{T}_{2} \mathrm{G}_{4}$ repeats presumably must be degraded before the addition of yeast $\mathrm{TG}_{1-3}$ can occur. Previous studies in our laboratory have shown that in rad52 strains, an $\mathrm{HO}$ endonuclease cut is followed by extensive $5^{\prime} \rightarrow 3^{\prime}$ exonuclease activity that can generate single-stranded $3^{\prime}$-ended strands as long as 10 kb (White and Haber 1990). Nevertheless, it was possible that the efficiency of new telomere formation could be improved by creating the DSB closer to the site of healing. We therefore repeated our experiments in an isogenic strain (YKK1010; Table 1) in which an HO cut site 
was placed just $1.6 \mathrm{~kb}$ distal to the $T_{2} \mathrm{G}_{4}$ repeats. We found that the frequency of healing by de novo telomere formation increased 10 -fold from $0.2 \%-2 \%$ (Table 2). Thus, the efficiency of de novo telomere formation increases with decreasing amounts of intervening DNA between the break site and the site of new telomere addition.

\section{Discussion}

Analysis of telomeric DNA sequences added de novo during the healing of broken yeast chromosomes leads us to propose that new $\mathrm{TG}_{1-3}$ repeats are added by the action of a telomerase rather than by recombination based on the following observations: First, new telomeres can be added in a $R A D 52$-independent manner at telomerelike G,T sequences that can be as short as a single G, GG, or GTG. Moreover, this addition is completely dependent on a nearby $\left(T_{2} G_{4}\right)_{13}$ organizing sequence. There are many equivalent short $\mathrm{G}, \mathrm{T}$ stretches in the $10 \mathrm{~kb}$ between the HO cut site and the $T_{2} G_{4}$ repeats, yet none of them are used as telomere addition sites. Moreover, although recombination between poorly matched DNA sequences can occur at very short regions of identical sequence (Mézard et al. 1992), those events require a more extensive homologous alignment of sequences and are $R A D 52$ dependent. Second, the fact that ADD1 and ADD2 are invariably added to the end of some primers (GGGTGTGG or TGGTGGTGG) but not to others (i.e., GGTGGGTGT or TGTGGTGGG) is consistent with the constraints imposed by a telomerase during the first steps of creating a new telomere but is difficult to reconcile with a recombinational model. This is especially evident when the sequence GGGTGTGG always specifies ADD1, but the same sequence with an additional T at the end does not. A further argument for the creation of new telomeres by telomerase comes from an analysis of the frequency with which the ADDl sequence is found directly after GGGTGTGG in nonjunctional telomere sequences. The sequence GGGTGTGG occurs 182 times in the more distal parts of the sequences analyzed (Fig. 3 and additional sequences not shown). In only 25 of these cases was GGGTGTGG followed by $\mathrm{ADD}$. In three other cases, the sequence was followed by ADD2. Thus, if new telomeres forming at GGGTGTGG were created by recombination, we would not have expected to find ADD1 at that site more than $\sim 14 \%$ of the time.

\section{A model for the creation of new telomeres adjacent to broken chromosome ends}

We propose that broken chromosomes are healed by the action of a yeast telomerase, as shown in Figure 4. We imagine that in the initial step the action of a $5^{\prime} \rightarrow 3^{\prime}$ exonuclease can degrade DNA from the site of the DSB until an appropriate primer region, in close proximity to the essential organizing sequence, is exposed. On the basis of the known mechanism of telomerase in Tetrahymena (Greider and Blackburn 1985, 1987; Blackburn

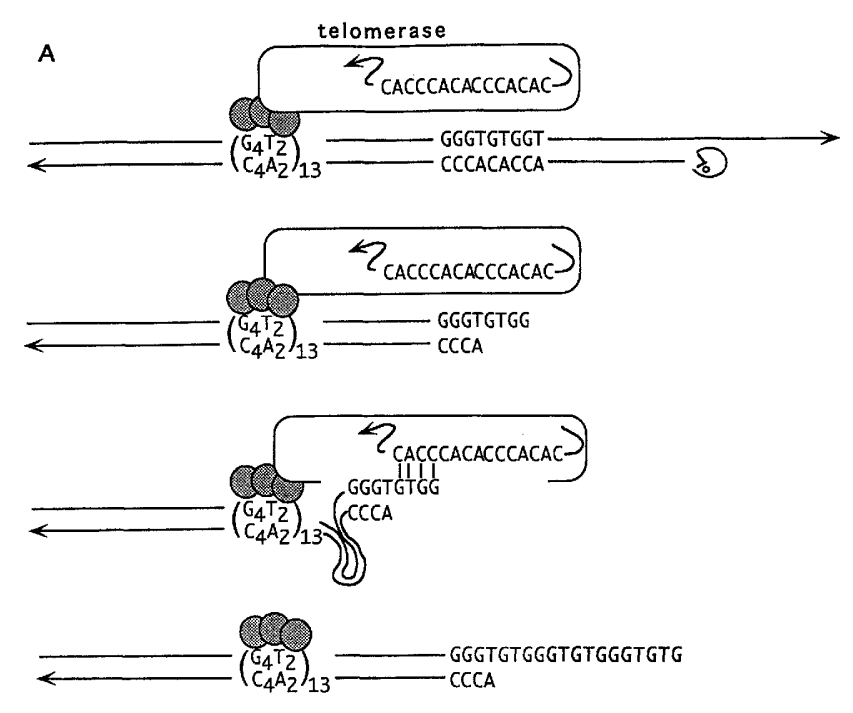

B

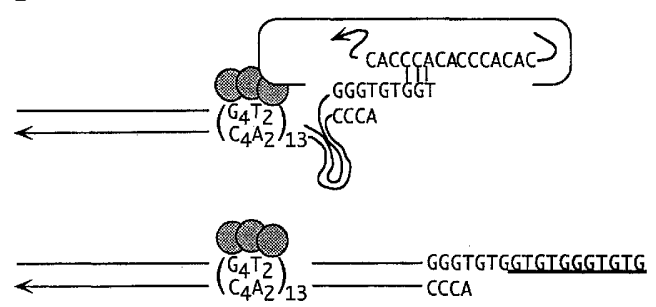

Figure 4. A model for the creation of a new telomere by telomerase. The telomerase RNA is shown associated with its protein component (large rectangle). Telomere binding proteins are represented as small circles. Telomerase recognizes the $\mathrm{T}_{2} \mathrm{G}_{4}$ repeats and/or these proteins. The end of the broken chromosome is degraded first by a $5^{\prime} \rightarrow 3^{\prime}$ exonuclease. And endo- or exonuclease may then remove the $3^{\prime}$ tail, thus exposing the primer. Once the DNA primer is exposed, the $3^{\prime}$ end of the RNA template anneals to the end of the primer. $(A)$ The primer ends in GTGG, which can specify the addition of ADDl. The DNA primer is extended by the addition of ADD1. (B) A primer not ending in GTGG aligns with the telomerase template in a different way and is extended by the telomerase such that ADD1 (underlined) is present overlapping the junction sequence.

1992) and the invariant addition of ADD1 and ADD2 to certain primers, we propose that the template RNA must include sequences complementary to ADDl and/or ADD2. In the model presented (Fig. 4), the pairing site of the telomerase RNA template is a $3^{\prime}$-CACC-5' because, as discussed above, primers with GTGG at their terminus appear to align the template more precisely, resulting in the systematic addition of the same new sequence. Apparently, other priming sites do not have bases that are precisely complementary to the primer binding site of the telomerase template and thus do specify the addition of the entire template sequence.

However, at other sites of addition, we postulate that the telomerase primer pairs to the internal part of the 11or 13-bp template (Fig. 4B). A strong prediction of this model is that ADD1 or ADD2 should overlap the junc- 
tion between the primer and newly added sequences. An examination of all junction sequences, described below (Fig. 5), confirms this prediction; in 37 of 44 examples, the junction between the chromosomal healing site and the new sequences contains either ADD1 or ADD2. In addition to the 16 instances in which ADD1 or ADD2 are appended directly to the chromosomal primer sequence GTGG (Fig. 5A), 21 of the 28 remaining healing events have either an $\mathrm{ADD} 1$ or $\mathrm{ADD} 2$ sequence overlapping the junction between the original and the newly added sequences (Fig. 5B). We note that in three cases listed at the top of this set, the same primer has been used to create both ADD1 and ADD2 junctions.

The last set (Fig. 5C) comprises five cases in which the new telomere sequences begin with one or more GT re-

\begin{tabular}{|c|c|c|}
\hline $5^{\prime}$ adjacent sequence & $\begin{array}{l}\text { sequences } \\
\text { at the addition site }\end{array}$ & $\begin{array}{l}\text { number of } \\
\text { events }\end{array}$ \\
\hline gggtgtgg & GTGTGGGTGTG & 7 \\
\hline tggtggtgg & GTGTGGGTGTG & 3 \\
\hline tggtgg & GTGTGGGTGTG & 1 \\
\hline tggtggtgg & GTGTGTGGGTGTG & 5 \\
\hline & & 16 \\
\hline \multicolumn{3}{|l|}{ B. } \\
\hline gggtgtg & gtGTGGGTGTG & 1 \\
\hline gggtgtg & gtGTGTGGGTGTG & 2 \\
\hline ggtgg & gtgtGGGTGTG & 2 \\
\hline ggtgg & gtgtGTGGGTGTG & 1 \\
\hline tgtggtgggc & gTGTGGGTGTG & 1 \\
\hline tgtggtgggc & gTGTGTGGGTGTG & 1 \\
\hline tgtggtgg & gTGTGGGTGTG & 2 \\
\hline tgtggt & gTGTGTGGGTGTG & 1 \\
\hline ttagggttagg & gTGTGTGGGTGTG & 1 \\
\hline ttagg & gTGTGTGGGTGTG & 1 \\
\hline ggtgggtgtc & gTGTGGGTGTG & 1 \\
\hline$g$ & gtgTGGGTGTG & 1 \\
\hline$g g$ & gtgTGGGTGTG & 1 \\
\hline gt & gTGTGGGTGTG & 1 \\
\hline acg & gTGTGTGGGTGTG & 1 \\
\hline $\operatorname{tg}$ & gTGTGTGGGTGTG & 1 \\
\hline gta & gtGTGGGTGTG & 1 \\
\hline \multirow[t]{2}{*}{ aga } & gtGTGTGGGTGTG & 1 \\
\hline & & 21 \\
\hline \multicolumn{3}{|l|}{ c. } \\
\hline gggtgtg & gtGTGGTGTG & 1 \\
\hline ggtggg & gtgtGGTGTG & 1 \\
\hline $\operatorname{tgg}$ & GTGTGGTGTG & 1 \\
\hline$g g$ & gtGTGGTGTG & 1 \\
\hline tgtggtgg & gTGTGGTGTG & 1 \\
\hline & & 5 \\
\hline \multicolumn{3}{|l|}{ D. } \\
\hline cta & gTGTGTGTGGGTGTG & 1 \\
\hline tgtggtgggc & gTGGTGTG & 1 \\
\hline & & 2 \\
\hline
\end{tabular}

Figure 5. Patterns of de novo $\mathrm{TG}_{1-3}$ addition. Chromosomal primer sequences for de novo telomere addition are highlighted, and newly added sequences are in uppercase letters as in Fig. 3. (A) Events in which complete ADD1 or ADD2 is added to chromosomal priming sites with GTGG at the $3^{\prime}$ end; $(B)$ events in which the ADD1 or ADD2 motif is present at the junction overlapping the primer and the newly added sequences; $(C)$ events in which GG rather than GGG is found in the first G cluster of newly added ADD3 telomere sequence GTGTGGTGTG. peats followed by GG rather than the GGG that is found in the 37 examples presented above. In these events we find that the junction of original and new sequences contains the sequence GTGTGGTGTG, which is a 10-bp variant of $\mathrm{ADD} 1$, lacking one of the three central $\mathrm{G}^{\prime}$ 's. This may represent another consensus sequence, ADD3. We note that in the more distal parts of the $\mathrm{TG}_{1-3}$ sequences we have analyzed, about $1 / 3(150 / 433)$ have $\left(\left.\mathrm{GT}\right|_{n} \mathrm{G}_{2}\right.$ and the rest have $(\mathrm{GT})_{n} \mathrm{G}_{3}$. Yet only 6 of 44 of the initial telomere sequences have GG. This is statistically significantly different $(P<0.05)$ from the overall frequency of GG versus GGG and again emphasizes that the initial addition of telomere sequences is more precisely dictated than random $\mathrm{TG}_{1-3}$ telomere sequences.

The two remaining events (Fig. 5D) do not fit easily into any category and illustrate the difficulty in generating a model that accounts for the unusual variability of the yeast telomere repeat. This difficulty is also evident in considering how sequences are added after the establishment of new telomeres with ADD1 or ADD2. For example, an inspection of the seven events in which ADD1 was added to GGGTGTGG in strains BX and BX1 fails to reveal a clear pattern of subsequent $T_{G_{1-3}}$ sequence addition. One cannot account for this variability by assuming that telomerase simply resynthesizes the $\mathrm{ADD} 1$ or $\mathrm{ADD} 2$ (or even $\mathrm{ADD} 3$ ) consensus with each new round of $\mathrm{TG}_{1-3}$ addition. This suggests that the mechanisms involved in the creation of a new telomere must be different, in some respects, from those involved in maintaining a preexisting telomere. One obvious difference is that existing telomeres contain many proteinbinding sites such as RAPl sites (Longtine et al. 1989; Liu and Tye 1991), which appear to play and important role in telomere maintenance (Longtine et al. 1989; Lustig et al. 1990; Sussel and Shore 1991; Kyrion et al. 1992). Preexisting telomeres may also form important tertiary structures, such as G-quartets (Williamson et at. 1989; Kang et al. 1992), which may play a role in telomere maintenance.

We have observed that in some cases, the same primer can be used to create both ADD1 and ADD2 junctions (Fig. 5). There might be a family of telomerase RNAs with each template specifying a different sequence, so that a the use of different templates would give rise to the irregular $\mathrm{TG}_{1-3}$. It has been suggested, on the basis of telomere sequence analysis, that multiple templates might exist in Paramecium and Plasmodium (Blackburn 1992). Alternatively, it is possible that one template can be aligned in two equally likely ways. In vitro studies of the human telomerase (Morin 1991) support the idea that flexibility in primer alignment might cause variability in patterns of addition, which in the case of yeast might be the characteristically variable $\mathrm{TG}_{1-3}$. In addition to these models, it has been suggested that $\mathrm{TG}_{1-3}$ irregularity could be caused by slippage on the RNA template (Shippen-Lenz and Blackburn 1989).

Although our results are best explained by the action of a telomerase, under special circumstances recombination between related, but not identical G,T repeats may play an important role in telomere formation. The direct 
joining between $T_{4} G_{4}$ and $T_{2} G_{4}$ sequences demonstrated by Wang and Zakian (1990b) argues strongly in favor of recombinational joining in this case. Quite likely both types of processes are possible, especially in the stabilization of transformed DNA.

\section{A role for an organizer sequence such as $\left(T_{2} G_{4}\right)_{n}$}

On the basis of our data and that of others (Murray et al. 1988; Shampay and Blackburn 1989), we propose that telomerase in yeast is incapable, itself, of establishing a new telomere. It requires the presence of an organizer sequence such as $\left(T_{2} G_{4}\right)_{n}$ nearby. This is similar to the results of in vitro studies of Tetrahymena telomerase (Harrington and Greider 1991), where new telomere sequences can be added at a distance from the $\mathrm{T}_{2} \mathrm{G}_{4}$ repeats. In contrast, an organizing sequence does not appear to be needed to add new telomeres at chromosomal truncations in malaria (Scherf and Mattei 1992) and humans (Wilkie et al. 1990; Morin 1991) and, in at least one developmental stage, Tetrahymena (Yu and Blackburn 19911 .

We imagine that certain proteins can bind to the organizer region [several possible candidate proteins have been identified (Liu and Tye 1991; Brigati et al. 1993)] and stabilize the interaction of yeast telomerase with short G,T stretches upstream, allowing them to be used as an initial primer of a new telomere. In some cases, additional proteins that bind to the primer itself may play an important role.

We have attributed the preferential addition of ADD1 and ADD2 at the beginnings of new telomeres to a preferred interaction with telomerase template RNA(s). It is also possible that the preferential appearance of ADD1 and $\mathrm{ADD} 2$ at these junctions does not come from preferential addition but from a preferential retention of these sequences. Newly formed telomeres may be degraded by exonucleases unless they have sufficient tertiary structure or are protected by associating with telomere-binding proteins such as RAPl (Lustig et al. 1990). In this view, only those additions of new sequences that established protein binding would be retained. The absence of preexisting telomere-binding proteins bound at the broken chromosome end may account for the imprecision of telomere addition (GGGG or TT) in the two cases noted above. In more distal regions of new telomeres we also found the presence of an A residue in BX39 and a TT in BX65 (Fig. 3A). These could also be errors of telomere addition but might also be attributable to PCR artifacts because only a single subclone from each of these strains was sequenced.

The system that we have set up will allow us to explore a number of other questions about the formation of new telomeres. For example, how is the DNA removed between the DSB and the site of new telomere addition? Our physical monitoring studies of homologous recombination induced by DSB (White and Haber 1990; Ray et al. 1991; Fishman-Lobell et al. 1992; Sugawara and Haber 1992) have all indicated that there is extensive $5^{\prime} \rightarrow 3^{\prime}$ exonuclease digestion of HO-cut DNA but little $3^{\prime} \rightarrow 5^{\prime}$ exonuclease activity. How, then, is the long $3^{\prime}-$ ended strand replaced by a telomere? In homologous recombination events, such nonhomologous DNA must be removed by an apparently endonucleolytic process that requires the UV repair RAD1 gene (Fishman-Lobell and Haber 1992). Experiments are under way to determine whether new telomere formation also requires this activity.

We are also interested in exploring the way in which the $T_{2} G_{4}$ region acts at a distance in the formation of new telomeres and what processes limit the efficiency of new telomere formation. If we can increase the efficiency of new telomere formation further, we should be able to follow these events by the same physical monitoring events used to describe HO-mediated recombination.

\section{Materials and methods}

Strains

Parental yeast strains are listed in Table 1. Strain PA104T was marked by an insertion of URA3::(TTGGGG) $13:: \mathrm{pBR} 322,10 \mathrm{~kb}$ proximal to the HO cut site in MATa. The insertion was constructed in plasmid $\mathrm{pJH} 154$ that contains a $3.5-\mathrm{kb}$ EcoRIBamHI chromosome III fragment in pBR322. This fragment was originally provided in phage $\lambda$ Charon 4A clone CP2 by John Larkin and John Woolford (Carnegie Mellon University, Pittsburgh, PA). The 1.1-kb URA3 gene (TTGGGG) ${ }_{13}$ and the $0.27-$ $\mathrm{kb}$ BamHI-HindIII fragment of pBR322 were inserted into the chromosome III segment at a unique HindIII site (see Fig. 1). This construct was then transplaced (Rothstein 1983) into chromosome III as an EcoRI-SalI fragment, with the nonhomologous SalI end being lost during recombination.

Strains YKK104BX1, YKK104BX2, and YKK104BX3 were constructed by replacing the pBR322 sequences in PA104T with BamHI-Xbal fragments BX1, BX2, and BX3 (Fig. 3). These sequence transplacements were accomplished by transformation of DNA fragments carrying $\mathrm{BX} 1, \mathrm{BX} 2$, and $\mathrm{BX} 3$ sequences flanked by chromosome III sequences into PA104T. Strain YKK $104 \mathrm{HO}$ was constructed by integrating a $2.6-\mathrm{kb}$ PvuIl fragment of the lacZ gene carrying an inserted 117-bp HO cut site (Fishman-Lobell et al. 1992) just distal to the pBR322 sequences in plasmid pJH154 so that the insert transplaced into chromosome III of PA104T carried an HO cut site $1.6 \mathrm{~kb}$ from the $T_{2} G_{4}$ repeats. Strain YKK104DTG was constructed by replacing URA3::(TTGGGG) ${ }_{13}:: \mathrm{pBR} 322$ with URA3::pBR322. All of these constructs involved transplacements into PA104T, a rad52 strain and, thus, were done after transformation with a CEN4 ARS1 plasmid carrying a HIS4 marker and a wild-type RAD52 gene (pKK5) to allow integration of transformed DNA. After integration of the relevant DNA fragment, pKK5 was lost by growth on YPD. All yeast transformations were done according to Schiestl and Gietz 1989).

Bacterial strains used were DB6507 $\left(\mathrm{r}^{-} \mathrm{m}^{-} \mathrm{pro}^{-} \mathrm{gal}^{-} \mathrm{recA}-\right.$ leu $B^{-}$thr ${ }^{-}$strr pyrF::Tn5) for selection of plasmids carrying $U R A 3$ and Escherichia coli SURE (uvrC umuC sbcC recl recB hsdR mcrt $A$ mcrB end $A$ mrr) and $\mathrm{MCl} 1061$ (hsdR mcrB araD139 $\triangle\left(a r a A B C^{-}\right.$leu $) 7679 \Delta l a c X 74$ galU galK rpsL thi) for selection of $a m p^{r}$ plasmids.

\section{Creation of DSBS}

Rich medium (YPD), nonfermentable medium (YP-lactate), and selective media (SD) were as described (Sherman et al. 1983; 
Rudin and Haber 1988). Terminally deleted chromosomes were isolated using two general strategies (see Fig. 1). 1) The DSB was generated in haploid PA104T, which was then mated to RS200L $\left(\mathrm{Rad}^{+}\right)$or YKK611 $\left(\mathrm{Rad}^{-}\right)$, and $\mathrm{Ura}^{+} \mathrm{Thr}^{-}$derivatives were selected for analysis. To generate the DSB, haploid strain PA104T was grown in YP-lactate medium, and $G A L:: H O$ gene on plasmid pFH800 (Nickoloff et al. 1989) was induced with $2 \%$ galactose for $1 \mathrm{hr}$. Cells were washed in YPD, pelleted, and mixed as a thick suspension with an approximately equal number of RS200L or YKK611 cells and allowed to mate overnight. Serial dilutions were plated on SD-Trp and grown for 2 days. Ura ${ }^{+}$ $\mathrm{Thr}^{-}$colonies were purified and subsequently analyzed. To ensure that $\mathrm{Ura}^{+} \mathrm{Thr}^{-}$derivatives came from independent events, only one isolate from each mating was retained. (2) The DSB was generated in diploid strains YKK910, YKK1010, YKK910BX1, YKK910BX2, or YKK910BX3 (Table 1) as described above. Ura ${ }^{+} \mathrm{Thr}^{-}$derivatives were selected for analysis. Serial dilutions were plated onto SD-Trp and allowed to grow for 2 days. Colonies were transferred to SD-Ura and SD-Thr and $\mathrm{Ura}^{+} \mathrm{Thr}^{-}$colonies were purified and subsequently analyzed. All incubations were at $30^{\circ} \mathrm{C}$.

\section{CHEF gel analysis}

Chromosomal DNA was separated on agarose gels as described (Carle and Olson 1985; Chu et al. 1986; Louis and Haber 1992). The chromosomal DNA was transferred to a Bio-Rad Zetaprobe nylon filter as per the manufacturer's instructions. Filters were hybridized with $U R A 3$ sequence probe $\left[\alpha^{-32} \mathrm{P}\right]$ CTP labeled by random primer extension (Feinberg and Vogelstein 1984. Southern 1975).

\section{$B A L 31$ digestion}

Fifty micrograms of genomic DNA was digested with 0.5 units of Bal31 nuclease (NEB) in a total volume of $500 \mu \mathrm{l}$ of $600 \mathrm{~mm}$ $\mathrm{NaCl}, 12 \mathrm{mM} \mathrm{CaCl}_{2}, 12 \mathrm{~mm}$ Tris $\mathrm{HCl}$ at $\mathrm{pH} 8.0,1 \mathrm{~mm}$ EDTA $\left(30^{\circ} \mathrm{C}\right)$. A $5-\mu \mathrm{g}$ sample was removed before addition of the enzyme and at 10 -min intervals after enzyme addition. Ten microliters of $0.25 \mathrm{M}$ EGTA was added to stop the reaction, and the DNA was precipitated with 2 volumes of ethanol. The DNA was pelleted, resuspended in $20 \mu \mathrm{l}$ of TE buffer, and digested with HindIII (NEB). The DNA was run on an $0.8 \%$ agarose gel, and the DNA was transferred to a Bio-Rad Zeta-probe nylon filter as per the manufacturer's instructions. Filters were hybridized with $\left[\alpha^{-32} \mathrm{P}\right]$ CTP- labeled URA3 sequence probe as described above.

\section{Cloning and sequencing of de novo telomeres}

The critical step in obtaining these sequences was to amplify the relevant DNA using PCR (Saiki et al. 1988). Because all of the more distal sequences were the highly repetitive yeast $\mathrm{TG}_{1-3}$ sequences, it was necessary to treat genomic DNA with BAL 31 exonuclease or T4 DNA polymerase to eliminate the $3^{\prime}$ overhang at the end of the chromosome (Henderson and Blackburn 1989; Wang and Zakian 1990a) and then ligate the telomere end to a unique template for PCR amplification. The amplified DNA was then subcloned into a sequencing vector to obtain sequences of the junction. In one case, the relevant sequences were cloned by ligation of the cloning vector pUC9 (Vieira and Messing 1982) directly onto the end of the chromosome after Bal31 treatment (Van der Ploeg et al. 1984).

Genomic DNA was treated in one of two ways.
Ligation to a double-stranded synthetic oligonucleotide A double-stranded oligonucleotide was made by allowing two complementary oligonucleotides to anneal

\section{oligo 1 , 5'-CATTTTGCTGCTGCCGGTCATTCGAACCC-3' oligo 2, 3'-GTAAAACGACGACGGCCAGTAAGCTTGGG-5'}

When annealed, these yield a 26-bp HindIII linker (HindIII site underlined). Approximately $5 \mu \mathrm{g}$ of genomic DNA was treated with 3 units of T4 DNA polymerase for $20 \mathrm{~min}$ at $16^{\circ} \mathrm{C}$ in a total volume of $50 \mathrm{ml}$ in $1 \times$ New England Biolabs (NEB) buffer 4, to create blunt DNA ends. T4 DNA polymerase was inactivated by incubation at $75^{\circ} \mathrm{C}$ for $10 \mathrm{~min}$. Three hundreded nanograms of T4-treated genomic DNA was ligated to $20 \mathrm{ng}$ of doublestranded oligonucleotide using NEB T4 DNA ligase in the buffer provided in a total volume of $50 \mu \mathrm{l}$ for $4 \mathrm{hr}$ or overnight at $16^{\circ} \mathrm{C}$. The EtOH-precipitated DNA was digested with HindIII and separated on a $0.5 \%$ agarose gel. HindIII fragments of $1.2-1.9 \mathrm{~kb}$ were cut out of the gel and purified using Prep-a-gene (Bio-Rad).

Circularization and amplification of a URA3-telomere region Approximately $5 \mu \mathrm{g}$ of genomic DNA was digested overnight with HindIII in a total volume of $400 \mu \mathrm{l}$. Digested DNA was treated with $1 \mathrm{mg} / \mathrm{ml}$ of RNase A for $30 \mathrm{~min}$. The digestion mixture was treated with $1: 1 \mathrm{vol} / \mathrm{vol}$ phenol/chloroform and precipitated in EtOH in the presence of $0.3 \mathrm{M}$ sodium acetate. The genomic DNA was then treated with T4 DNA polymerase as described above and then heat inactivated. The DNA was diluted to $\sim 2-3 \mu \mathrm{g} / \mathrm{ml}$ and incubated in the presence of NEB T4 DNA ligase in the buffer provided at $16^{\circ} \mathrm{C}$ for $4 \mathrm{hr}$ or overnight to promote intramolecular ligation. The DNA was then precipitated with $\mathrm{EtOH}$ in the presence of $0.3 \mathrm{M}$ sodium acetate and resuspended in TE buffer.

Following self-ligation or ligation to a double-stranded synthetic oligonucleotide, the DNA was amplified by PCR (Saiki et al. 1988) using a Techne Programmable Dri-Block PHC-1 temperature cycling machine. The oligonucleotides used were synthesized with a Cyclone V1. 05 synthesizer using phosphoramidite chemistry. Primers used for DNA amplifications were oligo 2 shown above, and

oligo 3, 5'-TTGGGGTCTGCCTCGCGG-3'

oligo 4, 5'-TCTGTGCTCCTTCCTTCGTTCTTC-3', a URA3 primer

The enzymes used for DNA amplification were either Pyrostase (Molecular Genetic Resources, Inc.) or Deep Vent Polymerase (NEB).

Primers were removed from the PCR product by treating with Prep-a-gene (Bio-Rad). The amplified DNA was subcloned into a pGem3Z vector (Promega). Sequencing was done directly from plasmid miniprep DNA isolated by the boiling method (Maniatis et al. 1983). Using the fmol sequencing kit, (Promega) $\sim 50$ ng of miniprep DNA was used in each sequencing reaction. In some cases, two or more subclones from the amplified DNA were sequenced (see Fig. 3). In every case where multiple subclones were sequenced, the initially added $\mathrm{TG}_{1-3}$ repeats were the same.

\section{Acknowledgments}

PA104T was constructed by Peter Avtges, RS200L was constructed by Ed Louis, and YKK901 was constructed by Jeanette Awenzstern. Mark Hearn and Michael Kluzcnik contributed to 
the construction of $\mathrm{pJH} 154$. Neal Sugawara and Vicki Lundblad were patient and very helpful readers of the manuscript. This research was funded by Department of Energy grant (DE-G0591ER61235). K.M.K. was a Trainee of Genetics Training Grant (GM07122).

The publication costs of this article were defrayed in part by payment of page charges. This article must therefore be hereby marked "advertisement" in accordance with 18 USC section 1734 solely to indicate this fact.

\section{References}

Biessmann, H. and J.M. Mason. 1992. Genetics and molecular biology of telomeres. Adv. Genet. 30: 185-249.

Blackburn, E.H. 1992. Telomerases. Annu. Rev, Biochem. 61: 113-129.

Blackburn, E.H. and J.W. Szostak. 1984. The molecular structure of centromeres and telomeres. Annu. Rev. Biochem. 53: 163-194.

Brigati, C., S. Kurtz, D. Balderes, G. Vidali, and D. Shore. 1993. An essential gene encoding a TTAGGG repeat-binding protein. Mol. Cell. Biol. 13: 1306-1314.

Carle, G.F. and M.V. Olson. 1985. An electrophoretic karyotype for yeast. Proc. Natl. Acad. Sci. 82: 3756-3760.

Chu, G., D. Volrath, and R.W. Davis. 1986. Separation of large DNA molecules by contour-clamped homogeneous electric fields. Science 234: 1582-1585.

Connolly, B., C.I. White, and J.E. Haber. 1988. Physical monitoring of mating type switching in Saccharomyces cerevisiae. Mol. Cell. Biol. 8: 2341-2349.

Dunn, B., P. Szauter, M.L. Pardue, and J.W. Szostak. 1984. Transfer of yeast telomeres to linear plasmids by recombination. Cell 39: 191-201.

Feinberg, A.P. and B. Vogelstein. 1984. Addendum: A technique for radiolabelling DNA restriction endonuclease fragments to high specific activity. Anal. Biochem. 132: 6 .

Fishman-Lobell, J. and J.E. Haber. 1992. Removal of nonhomologous DNA ends in double-strand break recombination: The role of the yeast ultraviolet repair gene RAD1. Science 258: 480-484.

Fishman-Lobell, J., N. Rudin, and J.E. Haber. 1992. Two alternative pathways of double-strand break repair that are kinetically separable and independently modulated. Mol. Cell. Biol. 12: 1292-1303.

Greider, C.W. and E.H. Blackburn. 1985. Identification of a specific telomere terminal transferase activity in Tetrahymeno extracts. Cell 43: 405-413.

- 1987. The telomere terminal transferase of Tetrahymena is a ribonucleoprotein enzyme with two kinds of primer specificity. Cell 51: 887-898.

- 1989. A telomeric sequence in the RNA of Tetrahymena telomerase required for telomere repeat synthesis. Nature 337: 331-337.

Haber, J.E. and P.C. Thornburn. 1984. Healing of broken linear dicentric chromosomes in yeast. Genetics 106: 207-226.

Haber, J.E., D. Mascioli, and D.T. Rogers. 1980. Illegal transposition of mating type genes in yeast. Cell 20: 519-528.

Harrington, L.A. and C.W. Greider. 1991. Telomerase primer specificity and chromosome healing. Nature 353: 451-456.

Hawthorne, D.C. 1963. A deletion in yeast and its bearing on the structure of the mating type locus. Genetics 48: 17271729.

Henderson, E. and E.H. Blackburn. 1989. An overhang $3^{\prime}$ terminus is a conserved feature of telomeres. Mol. Cell. Biol. 9: 345-348.
Jäger, D. and P. Philippsen. 1989. Stabilization of dicentric chromosomes in Saccharomyces cerevisiae by telomere addition to broken ends or by centromere deletion. EMBO J. 8: 247254.

Jensen, R. and I. Herskowitz. 1984. Directionality and regulation of cassette substitution in yeast. Cold Spring Harbor Symp. Quant. Biol. 49: 97-104.

Kämper, I., F. Meinhardt, N. Gunge, and K. Esser. 1989. In vivo construction of linear vectors based on killer plasmids from Kluyveromyces lactis: Selection of a nuclear gene results in attachment of telomeres. Mol. Cell. Biol. 9: 3931-3937.

Kang, C., X. Zhang, R. Ratliff, R. Moyzis, and A. Rich. 1992. Crystal structure of four-stranded Oxytricha telomeric DNA. Nature 356: 126-131.

Kyrion, G., K.A. Boakye, and A.J. Lustig. 1992. C-terminal truncation of RAP1 results in the deregualtion of telomere size, stability, and function in Saccharomyces cerevisiae. Mol. Cell. Biol. 12: 5159-5173.

Liu, Z. and B.K. Tye. 1991. A yeast protein that binds to vertebrate telomeres and conserved yeast telomeric junctions. Genes \& Dev. 5: 49-59.

Longtine, M.S., N.M. Wilson, M.E. Petracek, and J. Berman. 1989. A yeast telomere binding activity binds to two related telomere sequence motifs and is indistinguishable from RAP1. Curr. Genet. 16: 225-239.

Louis, E.J. and J.E. Haber. 1992. The structure and evolution of subtelomeric $\mathrm{Y}^{\prime}$ elements in Saccharomyces cerevisiae. Genetics 131: 559-574.

Lundblad, V. and J.W. Szostak. 1989. A mutant with a defect in telomere elongation leads to senescence in yeast. Cell 57: 633-643.

Lustig, A.J., S. Kurtz, and D. Shore. 1990. Involvement of the silencer and UAS binding protein RAPl in regulation of telomere length. Science 250: 549-553.

Maniatis, T., E.F. Fritsh, and J. Sambrook. 1983. Molecular cloning: A laboratory manual. Cold Spring Harbor Laboratory, Cold Spring Harbor, New York.

McClintock, B. 1941. The stability of broken ends of chromosomes in Zea mays. Genetics 26: 234-282.

McCusker, J.H. and J.E. Haber. 1981. Evidence of chromosomal breaks near the mating-type locus of Saccharomyces cerevisiae that accompany MAT $\alpha \times$ MAT $\alpha$ matings. Genetics 99: $383-403$.

Mézard, C., D. Pompon, and A. Nicolas. 1992. Recombination between similar but not identical DNA sequences during yeast transformation occurs within short stretches of identity. Cell 70: 659-670.

Morin, G.B. 1991. Recognition of a chromosome truncation site associated with $\alpha$-thalassaemia by human telomerase. $\mathrm{Na}$ ture 353: 454-456.

Müller, F., C. Wicky, A. Spicher and H. Tobler. 1991. Telomere formation after developmentally regulated chromosome breakage during the process of chromatin diminution in $\mathrm{As}$ caris lumbricoides. Cell 67: 815-822.

Murray, A.W., T.E. Claus, and J.W. Szostak. 1988. Characterization of two telomeric DNA processing reactions in Saccharomyces cerevisiae. Mol. Cell. Biol. 8: 4642-4650.

Nickoloff, J.A., J.D. Singer, M.F. Hoekstra and F. Heffron. 1989. Double-strand breaks stimulate alternative mechansims of recombination repair. J. Mol. Biol. 207:527-541.

Pluta, A.F. and V.A. Zakian. 1989. Recombination occurs during telomere formation in yeast. Nature 337: 429-433.

Pologe, L.G. and J.V. Ravetch. 1988. Large deletions resulting from breakage and healing of $P$. falciparum chromosomes. Cell 55: 869-874.

Prowse, K.R., A.A. Avilion, and C.W. Greider. 1993. Identifica- 
tion of a nonprocessive telomerase activity from mouse cells. Proc. Natl. Acad. Sci. 90: 1493-1497.

Ray, B.L., C.W. White, and J.E. Haber. 1991. Heteroduplex formation and mismatch repair of the "stuck" mutation during mating-type switching in Saccharomyces cerevisiae. Mol. Cell. Biol. 11: 5372-5380.

Rothstein, R.J. 1983. One-step gene disruption in yeast. Methods Enzymol. 101: 202-211.

Rudin, N. and J.E. Haber. 1988. Efficient repair of HO-induced chromosomal breaks in Saccharomyces cerevisiae by recombination between flanking homologous sequences. Mol. Cell. Biol. 8: 3918-3928.

Saiki, R.K., D.H. Gelfand, S. Stoffel, S.J. Scharf, R. Higuchi, G.T. Horn, K.B. Mullis, and H.A. Erlich. 1988. Primer-directed enzymatic amplification of DNA with a thermostable DNA polymerase. Science 239: 487-491.

Scherf, A. and D. Mattei. 1992. Cloning and characterization of chromosomal breakpoints of Plasmodium falciparum: Breakage and new telomere formation occurs frequently and randomly in subtelomeric genes. Nucleic Acids Res. 20: 1461-1466.

Schiestl, R.H. and R.D. Gietz. 1989. High efficiency transformation of intact yeast cells using single stranded nucleic acids as carrier. Curr. Genet. 16: 337-346.

Shampay, J. and E.H. Blackburn. 1989. Tetrahymena micronuclear sequences that function as telomeres in yeast. Nucleic Acids Res. 17: 3247-3260.

Shampay, J.J., J.W. Szostak, and E.H. Blackburn. 1984. DNA sequences of telomeres maintained in yeast. Nature 310: 154-157.

Sherman, F., G.R. Fink, and J.B. Hicks. 1983. Methods in Yeast Genetics Cold Spring Harbor Laboratory, Cold Spring Harbor, New York.

Shippen-Lenz, D. and E.H. Blackburn. 1989. Telomere terminal transferase activity in the hypotrichous ciliate Euplotes crassus. Mol. Cell. Biol. 9: 2761-2764.

Sokal, R.R. and F.J. Rohlf. 1969. Biometrics W.H. Freeman, San Francisco, CA.

Southern, E.M. 1975. Detection of specific sequences among DNA fragments separated by gel electrophoresis. I. Mol. Biol. 98: 503-517.

Sugawara, N. and J.E. Haber. 1992. Characterization of doublestrand break-induced recombination: Homology requirements and single-strand DNA requirements. Mol. Cell. Biol. 12: $563-575$.

Surosky, P.K., S.C. Newlon, and B. Tye. 1986. The mitotic stability of deletion derivatives of chromosome III in yeast. Proc. Natl. Acad. Sci. 83: 414-418.

Sussel, L. and D. Shore. 1991. Separation of transcriptional activation and silencing functions of the RAPl-encoded repressor/activator protein 1: Isolation of viable mutants affecting both silencing and telomere length. Proc. Natl. Acad. Sci. 88: $7749-7753$.

Szostak, J.W. and E.H. Blackbum. 1982. Cloning yeast telomeres on linear plasmid vectors. Cell 29: 245-255.

Van der Ploeg, L.H.T., A.Y.C. Liu, and P. Borst. 1984. Structure of the growing telomeres of Trypanosomes. Cell 36: 459468.

Vieira, J. and J. Messing. 1982. The pUC plasmids, and M13mp7-derived system for insertion mutagenesis and sequencing with synthetic universal primers. Gene 19: 259268.

Wang, S. and V.A. Zakian. 1990a. Sequencing of Saccharomyces telomeres cloned using T4 DNA polymerase reveals two domains. Mol. Cell. Biol. 10: 4415-4419.

- 1990b. Telomere-telomere recombination provides an express pathway for telomere acquisition. Nature 345: 456458.

Weiffenbach, B. and J.E. Haber. 1981. Homothallic mating type switching generates lethal chromosome breaks in rad52 strains of Saccharomyces cerevisiae. Mol. Cell. Biol. 1: 522534.

Weiffenbach, B., D.T. Rogers, J.E. Haber, M. Zoller, D.W. Russell, and M. Smith. 1983. Deletions and single base pair changes in the yeast mating type locus that prevent homothallic mating type conversions. Proc. Natl. Acad. Sci. 30: 3401-3405.

White, C.I. and J.E. Haber. 1990. Intermediates of recombination during mating type switching in Saccharomyces cerevisiae. EMBO J. 9: 663-673.

Wilkie, A.O., J. Lamb, P.C. Harris, R.D. Finney and D.R. Higgs. 1990. A truncated human chromosome 16 associated with alpha thalassaemia is stabilized by addition of telomeric repeat (TTAGGG) . Nature 346: 868-871.

Williamson, J.R., M.K. Raghuraman, and T.R. Cech. 1989. Monovalent cation-induced structure of telomeric DNA: The G-quartet model. Cell 59: 871-880.

Yu, G.L. and E.H. Blackburn. 1991. Developmentally programmed healing of chromosomes by telomerase in Tetrahymena. Cell 67: 823-832.

Zahler, A.M. and D.M. Prescott. 1988. Telomere terminal transferase activity in the hypotrichous ciliate Oxytricha nova and a model for replication of the ends of linear DNA molecules. Nucleic Acids Res. 16: 6953-6985.

Zakian, V.A., H.M. Blanton, and G.M. Dani. 1985. Formation and stability of linear plasmids in recombination deficient strain of yeast. Curr. Genet. 9: 441-445.

Zakian, V.A. 1989. Structure and function of telomeres. Annu. Rev. Genet. 23: 579-604. 


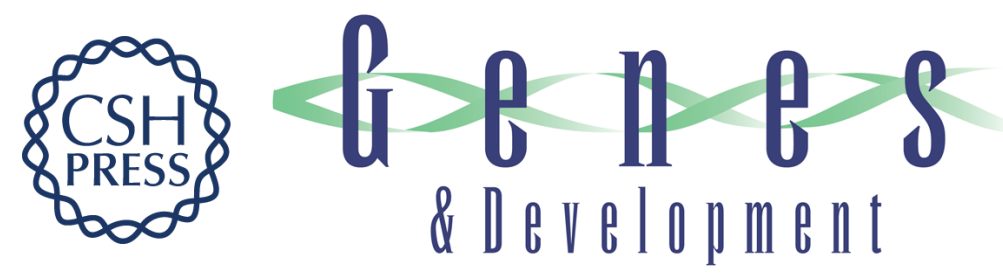

\section{New telomeres in yeast are initiated with a highly selected subset of TG1-3 repeats.}

K M Kramer and J E Haber

Genes Dev. 1993, 7:

Access the most recent version at doi:10.1101/gad.7.12a.2345

References

This article cites 66 articles, 27 of which can be accessed free at: http://genesdev.cshlp.org/content/7/12a/2345.full.html\#ref-list-1

\section{License}

Email Alerting

Receive free email alerts when new articles cite this article - sign up in the box at the top Service right corner of the article or click here.

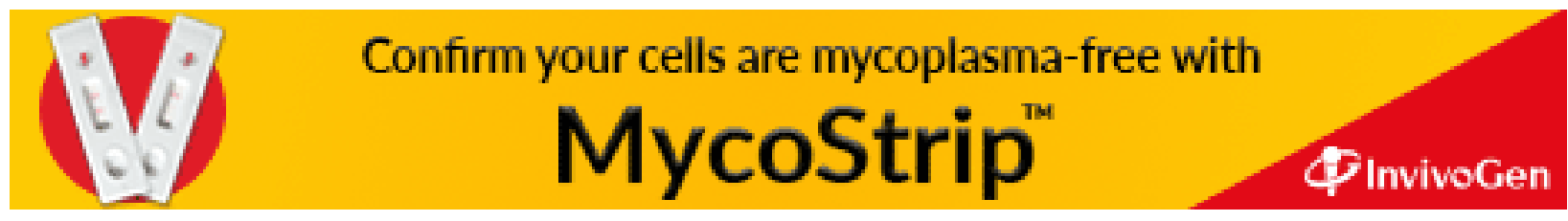

